\title{
Conditioning the Heat Treatment of A356 Aluminium Alloy and Validation of Wear Rate for Brake Disc Application
}

\author{
O. B. Umaru, J. S. Jatau, M. H. Muhammad, A. Tokan \\ Department of Mechanical/Production Engineering, \\ Abubakar Tafawa Balewa University, \\ Bauchi- Nigeria
}

\begin{abstract}
The use of Taguchi optimization process in conditioning the heat treatment of $\mathbf{A 3 5 6}$ aluminium alloy was done in this study. The alloy was chill cast and solution heat treated. The rice husk/ash was analyzed before and after ashing using textural analysis (BET), X-ray fluorescence (XRF) analysis and $X$-ray diffractometry analysis respectively. The heat treated samples were characterized for wear resistance properties. The textural analysis showed an enhanced rice husk condition, XRF and XRD result indicated the presence of silica (SiO2) as the major component of the rice husk/ash produced. Nine experimental runs were obtained with run 4 having the lowest wear rate of $0.5208 \mathrm{~mm} 3 / \mathrm{n} / \mathrm{m}$. The optimization analysis employed indicates a possible improvement of $5.139 \%$. The as cast and conventionally heat treated samples indicated a wear rate of $0.7886 \mathrm{~mm} 3 / \mathrm{n} / \mathrm{m}$ and $0.5887 \mathrm{~mm} 3 / \mathrm{n} / \mathrm{m}$ respectively. The improvement is as a result of the formation of silicon metal, which dissolves in the aluminium alloy. In conclusion, the results from the confirmation experiments using the optimal parameters confirm that solution heat treatment in the presence of rice husk ash followed by ageing treatment can be used to improve the wear resistance of the material under study.
\end{abstract}

Keywords: Rice husk ash; Solution heat treatment; Control factors; Taguchi analysis

\section{INTRODUCTION}

Grey cast iron which is the conventional material for the production of brake disc has associated setbacks of high density that leads to high consumption of energy in automobiles during braking system [1-2]. Therefore, attention has been turned to use of composite and nonferrous alloys [3-4]. However, composite has a major problem of cost, while nonferrous alloys are soft with low wear resistance [4-5]. To overcome these drawbacks, coating and heat treatment are adopted. The use of coating is a slow process, hence time wasting [3-5]. Also, were heat treatment has been used, no optimization of the process parameters was reported.

In recent time, the use of aluminium alloy have gained interest in brake disc application by coating it with oxides that are cheaply available. [6] worked on the optimization of alumina coated lightweight brake rotor. In his work, a sensitivity approach based on the Taguchi analysis was carried out to investigate the effect of various parameters on the thermal performance of a typical brake disc. Wrought aluminium disc brake rotors coated with alumina on the rubbing surface were determined to have better potential of replacing the conventional cast iron rotor with a reasonable cost.

However processed and conditioned monolithic aluminium alloys have also regained attention in automobile engineering applications due to some excellent properties displayed [7-9]. As a guide, isothermal treatment has been claimed as a tool to enhance better electromechanical properties. Although one of the major problems encountered in the use of aluminium alloy is the overheating and softening of the material due to its low melting point [3-6]. Taguchi identifies the design of the experiment as a means of assessing all possible methods or designs to achieve the desired goal as efficiently and reliably. The Taguchi analysis was used by [3] to detect the effects of different brake disc parameters on thermal efficiency. This result was then used to optimize the design of light weight brake discs to reduce weight and improve thermal efficiency. It is extremely difficult to perform numeric tests for each combination of the design variables, so aggregate modeling is used under these circumstances. This leads to simulation analysis in certain points in the sample in the design area and the creation of predictable surface that will then be used for optimization analysis [10]. In this research, agro-waste was used to condition and improve on the conventional heat treatment process in order to modify the alloy properties leading to high integrity aluminium alloy formation using hardness and wear as criteria via Taguchi design analysis.

\section{EXPERIMENTAL DETAILS}

\subsection{Rice Husk/Ash Preparation}

Ricehusk was collected from a rice plantation in ZariaNigeria, poured into crucibles which was later placed in the muffle furnace for combustion in an air tight condition to $600^{\circ} \mathrm{C}$. The ash obtained at this temperature were allowed to cool in the muffle furnace for 24-30 hours to room temperature. The ricehusk/ash was then analyzed for textural analysis, using Brunaver-Emmett-Teller (BET) method, chemical composition, using X-ray Fluorescence (XRF) machine and phases determination, using X-ray diffractometry (XRD) machine.

\subsection{A356 Aluminium Alloy Production}

Following the method described in [10], the high purity aluminium wire with charge calculation shown in Table 1 
was melted in a muffle resistance furnace that was allowed to heat to $750^{\circ} \mathrm{C}$. The crucible was then removed from the furnace, and the alloying elements added before returning to the furnace for further 30 minutes, during which the furnace temperature will have raised to $800^{\circ} \mathrm{C}$ for superheat to occur. Elemental sodium $(0.01 \% \mathrm{Na})$ was then added and stirred thoroughly before pouring into the produced mold.

Table 1: Charge calculation (wt. \%) of the proposed chill cast A356 aluminium alloy

Source: [11]

\begin{tabular}{llll}
\hline Element & $\mathrm{Al}$ & $\mathrm{Si}$ & $\mathrm{Mg}$ \\
\hline Wt. $\%$ & 92.05 & 7.50 & 0.45 \\
\hline
\end{tabular}

\subsection{Experimental Design of the Heat Treatment Process}

L9-Taguchi design was employed to optimize the chosen key factors namely: solution heat treatment (SHT) temperature and time, and ageing temperature and time, in relation to the response which are hardness and wear rate. Table 2 shows the levels of the factors used in the experiment

Table 2: Levels of the Factors used in the Experiment

\begin{tabular}{lllll}
\hline Control factor & level & & & \\
\cline { 2 - 5 } & 1 & 2 & 3 & units \\
\hline A: SHT temperature & & & & \\
B: SHT time & 500 & 540 & 580 & ${ }^{\circ} \mathrm{C}$ \\
C: AGEING temperature & 30 & 60 & 90 & mins \\
D: AGEING time & 160 & 180 & 200 & ${ }^{\circ} \mathrm{C}$ \\
\hline
\end{tabular}

Nine experiments were performed as illustrated in Table 3 according to the Taguchi design of experiment with 4 factors and 3 levels of each factor. In each case, three experimental runs was conducted in order to obtain an average value.

Table 3: L9 Taguchi Matrix of the Heat Treatment Process

\begin{tabular}{|c|c|c|c|c|}
\hline \multirow{2}{*}{$\begin{array}{l}\text { Expt. } \\
\text { No. }\end{array}$} & \multicolumn{3}{|c|}{ Factors } & \\
\hline & $\begin{array}{l}\text { SHT } \\
\text { tempt }\left({ }^{\circ} \mathrm{C}\right)\end{array}$ & $\begin{array}{l}\text { SHT } \\
\text { time }(\min )\end{array}$ & $\begin{array}{l}\text { Ageing } \\
\text { tempt }\left({ }^{\circ} \mathrm{C}\right)\end{array}$ & $\begin{array}{l}\text { Ageing } \\
\text { Time (min) }\end{array}$ \\
\hline 1 & 500 & 30 & 160 & 60 \\
\hline 2 & 500 & 60 & 180 & 120 \\
\hline 3 & 500 & 90 & 200 & 180 \\
\hline 4 & 540 & 30 & 180 & 180 \\
\hline 5 & 540 & 60 & 200 & 60 \\
\hline 6 & 540 & 90 & 160 & 120 \\
\hline 7 & 580 & 30 & 200 & 120 \\
\hline 8 & 580 & 60 & 160 & 180 \\
\hline 9 & 580 & 90 & 180 & 60 \\
\hline
\end{tabular}

2.4 Conditioning the Heat Treatment Process of the Alloy Using the Taguchi Design Obtained

The A356 aluminium alloy were embedded in a steel pot containing the rice husk ash. The steel pot was tightly sealed with clay cover to prevent the escape of carbon and unwanted furnace gas from entering the steel pot during heating. Solution heat treatment was then performed at temperatures of $\left(500,540\right.$ and $\left.580^{\circ} \mathrm{C}\right)$ and time of $(30,60$ and 90 mins). The A356 aluminium alloy was immediately removed from the steel box and quenched in warm water $\left(60^{\circ} \mathrm{C}\right)$ followed by ageing at temperatures of $(160,180$ and $200^{\circ} \mathrm{C}$ ) for ageing times of $(60,120$ and $180 \mathrm{mins})$ as presented in Table 3.

In order for large number of variables to be studied with a smaller number of experiment, Taguchi utilizes an orthogonal array from the design of experiment theory. The conclusions drawn from these small scaled experiment become valid over the entire region of the experiment conducted by setting the control factors [12]. Orthogonal array is not new in design of experiment, but Taguchi have simplified the use of orthogonal array and there corresponding linear graphs to fit specific conditions of the analysis. Example of standard orthogonal; arrays are L4, L8, L12, L16, L32 and L64 all of these at 2 levels, and L9, L18 and L27, all at 3 and 2 levels. L16 and L32 are modified at 4 levels, while L25 is used at 5 levels [13].

The total degrees of freedom has to be computed in order to select an orthogonal array to be used in the experiment. The degrees of freedom can be defined as the number of comparisms between these process parameters that will determine the better level and specifically how much better it is. After determining the degree of freedom, an appropriate orthogonal array is then selected to fit the specific task.

One difference between Taguchi and other optimal process is the use of a signal to noise ratio. The idea here is that apart from maximizing the mean (signal), it is also important to minimize the process variations (noise) which are both achievable using the $\mathrm{S} / \mathrm{N}$ ratio [14]. Determining the effect of each factor on the responses will involve calculating the 
$\mathrm{S} / \mathrm{N}$ ratio of each factor. The signals indicated that the sensitivity of the experiment output to the noise factors were measured from its effect on the average responses and the noise. Selecting the required $\mathrm{S} / \mathrm{N}$ ratio depends on the mean square deviation (MSD) for analyzing repeated results. The
MSD which is consistent with Taguchi quality objective combines variation around the given target [15-16]. The relationships existing among the observed results, MSD and $\mathrm{S} / \mathrm{N}$ ratio are summarized below

$$
\begin{aligned}
& M S D=\frac{\left(\left(Y_{1}-\bar{Y}\right)^{2}+\left(Y_{2}-\bar{Y}\right)^{2}+\ldots \ldots\left(Y_{n}-\bar{Y}\right)^{2}\right)}{n} \quad \ldots \ldots \ldots \ldots \ldots \ldots \text { For nominal is better } \\
& M S D=\frac{\left(Y_{1}^{2}+Y_{2}^{2}+\ldots \ldots . .+Y_{n}^{2}\right)}{n} \quad \ldots \ldots \ldots \ldots \ldots . . \text { For smaller is better }
\end{aligned}
$$

$M S D=\frac{\left(\frac{1}{Y_{1}^{2}}+\frac{1}{Y_{2}^{2}}+\ldots \ldots . .+\frac{1}{Y_{n}^{2}}\right)}{n}$

$S / N=-10 \log (M S D)$ For bigger is better For all characteristics

Where: $Y=$ Observed data, $\bar{Y}=$ Average of the observed data and $n=$ Number of observations

Analysis of variance, ANOVA is generally used in studying the relationships existing amongst the sampled data. It makes it possible to analyze the difference between two or more sample means. The ANOVA is achieved by subdividing the total sum of squares. One way ANOVA is the simplest case. Generally, ANOVA is similar to regression as it is used in investigating and modelling the relationship existing between a response variable and the independent variables [17].

From the $\mathrm{S} / \mathrm{N}$ analysis and mean response characteristics, the optimum levels of the control factors can be calculated. Hence, the predicted mean of quality characteristics can be calculated using the relationship below [18].

$$
S_{o p t}=\bar{Y}+\left(\bar{A}_{2}-\bar{Y}\right)+\left(\bar{B}_{1}-\bar{Y}\right)+\left(\bar{C}_{1}-\bar{Y}\right)
$$

Where: $\bar{Y}=$ Total average of performance characteristics (in this case, corresponding to all the $27(9 \times 3)$ readings, $\bar{A}_{2}$ $\bar{B}_{1}$ and $\bar{C}_{1}$ are the average values of the materials wear, friction and hardness

$S_{\text {opt }}=$ Predicted mean of the Al-Si-Mg alloys wear, friction and hardness at optimum conditions

The optimization allows the industrial user to easily repeat with negligible error the optimal condition and process parameters in achieving the desired properties. It searches for a combination of factor levels that can satisfy the conditions of the individual factors and responses. The final step involves predicting and verifying the improvement in terms of responses, using the optimal conditions of the process parameters.

\subsection{Wear Rate Analysis of the Heat Treated Samples}

The wear analysis was carried out on the surface of the samples using a ball on disc Anton Paar GmbH tribometer. This test was conducted according to ASTM G190-15 and ASTM G115-10 standards. In this test, a fixed ball-shaped body (stainless steel) is loaded on top of the rotating disclower specimen (A356 aluminium alloy) under the following conditions load of $5 \mathrm{~N}$, speed of 250rpm, distance of $7.95 \mathrm{~m}$ and a dwell time of 1 minute in accordance with literature [7]. All the test was performed at room temperature and under unidirectional (clockwise) motion.

\section{RESULTS AND DISCUSSION}

\subsection{Textural Analysis (BET) of the Rice Husk Ash Used} The textural analysis was done in a Nova station B instrument, using Nitrogen gas at an exit temperature of $250^{\circ} \mathrm{C}$ and time of 3 hours. The sample volume was $1 \mathrm{cc}$ with a weight of $0.12 \mathrm{~g}$ and time of analysis was 114.9 minutes. Figure 1 show the data reduction parameters using the DA method in a nitrogen gas at a temperature of $77.350 \mathrm{k}$, $16.200 \mathrm{~A}^{\mathrm{o}}$ cross section and a liquid density of $0.808 \mathrm{~g} / \mathrm{cc}$. From the analysis in Figure 1, it is evident that at a smaller diameter, the pore volume remain unchanged while at a bigger diameter beyond $1600 \mathrm{~nm}$ pore diameter, volume increases drastically indicating a high peak of 0.1300 $\mathrm{cc} / \mathrm{mm} / \mathrm{g}$. However, at an increased pore diameter of the ash, the volume decreased drastically corresponding to $6000 \mathrm{~nm}$ pore diameter. This also indicate that rice husk of higher diameter within the matrix have higher diffusion rate which means enhanced rice husk condition or property. 


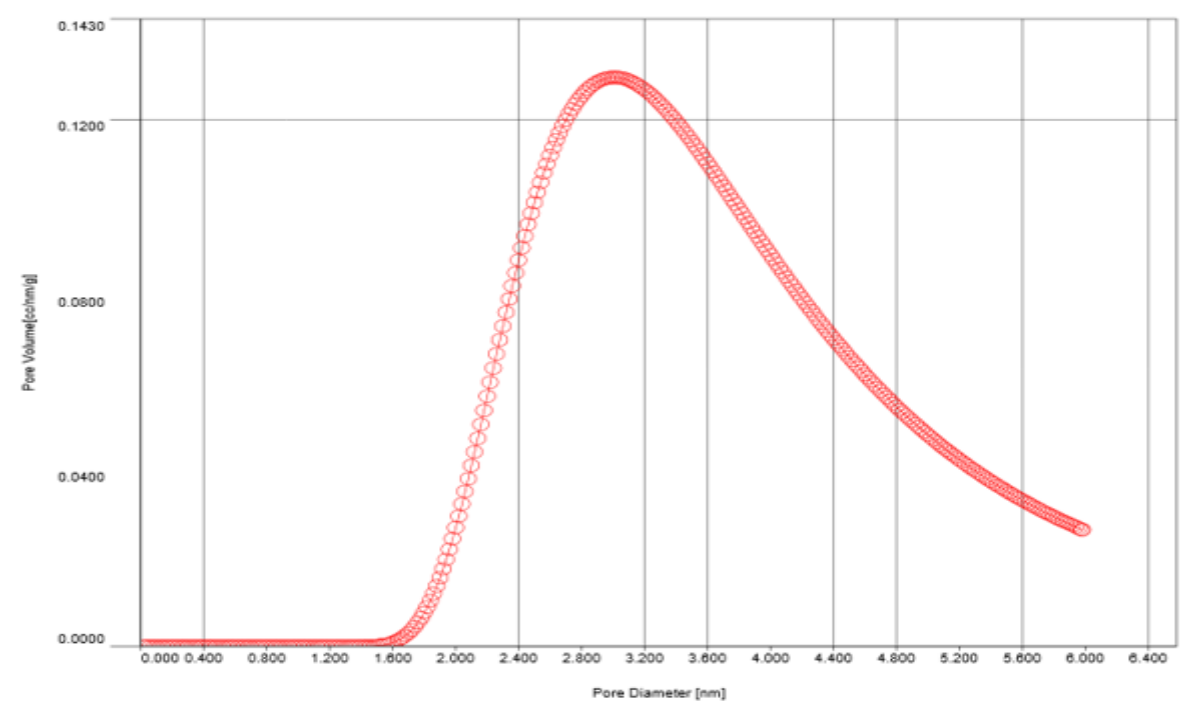

Figure 1: Data reduction parameters using the DA method

Equally, the surface area, pore volume and pore size using the textural analysis have been comprehensively summarized in plate 1. The surface area data using various method range from $1.344 \times 10^{4} \mathrm{~m}^{2} / \mathrm{g}$ (Lagmore surface data) to $8.714 \times 10 \mathrm{~m}^{2} / \mathrm{g}(\mathrm{DFT}$ cumulative surface area), pore volume from $9.279 \times 10^{-3} \mathrm{cc} / \mathrm{g}$ (SF method) to $5.757 \times 10^{-2} \mathrm{cc} / \mathrm{g}$ (HK method) and pore size from $1.847 \mathrm{~nm}$ (HK method) to $6.538 \mathrm{~nm}$ (DR method).

\section{Area-Volume Summary}

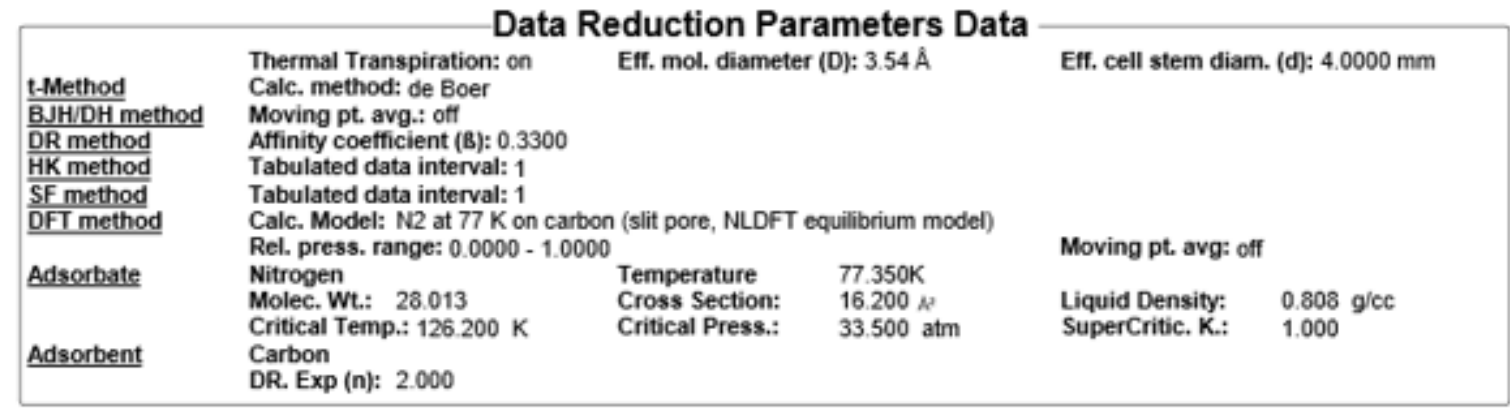

\begin{tabular}{|c|c|}
\hline \multicolumn{2}{|l|}{ Surface Area Data } \\
\hline $\begin{array}{l}\text { SinglePoint BET } \\
\text { Multipoint BET. } \\
\text { Langmuir surface area. } \\
\text { BJH method cumulative adsorption surface area. } \\
\text { DH method cumulative adsorption surface area. } \\
\text { t-method external surface area. } \\
\text { DR method micropore area. } \\
\text { DFT cumulative surface area. }\end{array}$ & $\begin{array}{l}2.272 \mathrm{e}+02 \mathrm{~m}^{2} / \mathrm{g} \\
4.183 \mathrm{e}+02 \mathrm{~m}^{2} / 9 \\
1.344 \mathrm{e}+04 \mathrm{~m}^{2} / \mathrm{g} \\
4.271 \mathrm{e}+02 \mathrm{~m}^{2} / \mathrm{g} \\
4.532 \mathrm{e}+02 \mathrm{~m}^{2} / 9 \\
4.183 \mathrm{e}+02 \mathrm{~m}^{2} / 9 \\
4.150 \mathrm{e}+02 \mathrm{~m}^{2} / 9 \\
8.714 \mathrm{e}+01 \mathrm{~m}^{2} / 9\end{array}$ \\
\hline \multicolumn{2}{|l|}{ Pore Volume Data } \\
\hline $\begin{array}{l}\text { BJH method cumulative adsorption pore volume } \\
\text { DH method cumulative adsorption pore volume } \\
\text { DR method micropore volume. } \\
\text { HK method micropore volume. } \\
\text { SF method micropore volume.... } \\
\text { DFT method cumulative pore volume }\end{array}$ & $\begin{array}{l}2.111 \mathrm{e}-01 \mathrm{colg} \\
2.158 \mathrm{e}-01 \mathrm{colg} \\
1.475 \mathrm{e}-01 \mathrm{colg} \\
5.757 \mathrm{e}-02 \mathrm{colg} \\
9.279 \mathrm{e}-03 \mathrm{colg} \\
1.056 \mathrm{e}-01 \mathrm{colg}\end{array}$ \\
\hline \multicolumn{2}{|l|}{ Pore Size Data } \\
\hline $\begin{array}{l}\text { BJH method adsorption pore Diameter (Mode Dv(d)) } \\
\text { DH method adsorption pore Diameter (Mode Dv(d)) } \\
\text { DR method micropore Pore vidth. } \\
\text { DA method pore Diameter (Mode) } \\
\text { HK method pore Diameter (Mode) } \\
\text { SF method pore Diameter (Mode). } \\
\text { DFT pore Diameter (Mode)...... }\end{array}$ & $\begin{array}{l}2.100 \mathrm{e}+00 \mathrm{~nm} \\
2.427 \mathrm{e}+00 \mathrm{~nm} \\
6.538 \mathrm{e}+00 \mathrm{~nm} \\
3.000 \mathrm{e}+00 \mathrm{~nm} \\
1.847 \mathrm{e}+00 \mathrm{~nm} \\
3.479 \mathrm{e}+00 \mathrm{~nm} \\
2.647 \mathrm{e}+00 \mathrm{~nm}\end{array}$ \\
\hline
\end{tabular}

Plate 1: Area-Volume summary of the textural analysis 
3.2 XRF Analysis of the Rice Husk/Ash Used in these Study

The XRF analysis as shown in Tables 4-6 indicated that the rice husk without ashing had $\mathrm{SiO}_{2}$ composition of $27.3418 \%$, which increased to $63.166 \%$ after ashing and
$79.3412 \%$ after usage in the heat treatment of the metal. Other detectives in their study was $\mathrm{K}_{2} \mathrm{O}$ ranging from 0.9702 to $1.0682 \%$ respectively and some other traces of oxides.

Table 4: XRF Analysis of Rice Husk used in this study

\begin{tabular}{lll}
\hline $\mathrm{S} / \mathrm{N}$ & $\mathrm{Component}$ & Mass $(\%)$ \\
\hline 1. & $\mathrm{SiO}_{2}$ & 27.3418 \\
2. & $\mathrm{P}_{2} \mathrm{O}_{5}$ & 0.4863 \\
3. & $\mathrm{~K}_{2} \mathrm{O}$ & 0.9702 \\
4. & $\mathrm{CaO}$ & 0.2634 \\
5. & $\mathrm{MnO}$ & 0.0496 \\
6. & $\mathrm{Fe}_{2} \mathrm{O}_{3}$ & 0.2097 \\
7. & $\mathrm{NiO}$ & 0.0434 \\
8. & $\mathrm{SrO}$ & 0.0405 \\
9. & $\mathrm{Nb}_{2} \mathrm{O}_{5}$ & 0.0458 \\
10. & $\mathrm{MoO}_{3}$ & 0.2209 \\
11. & $\mathrm{Ag}_{2} \mathrm{O}$ & 0.0210 \\
12. & $\mathrm{CdO}^{13}$ & 0.1143 \\
14. & $\mathrm{Sb}_{2} \mathrm{O}_{5}$ & 0.0270 \\
\hline
\end{tabular}

Table 5: XRF Analysis of Rice Husk ash produced

\begin{tabular}{lll}
\hline $\mathrm{S} / \mathrm{N}$ & $\mathrm{Component}$ & Mass $(\%)$ \\
\hline 1. & $\mathrm{SiO}_{2}$ & 63.1660 \\
2. & $\mathrm{P}_{2} \mathrm{O}_{5}$ & 0.4454 \\
3. & $\mathrm{~K}_{2} \mathrm{O}$ & 1.0682 \\
4. & $\mathrm{MnO}$ & 0.0783 \\
5. & $\mathrm{Fe}_{2} \mathrm{O}_{3}$ & 0.2318 \\
6. & $\mathrm{NiO}$ & 0.0322 \\
7. & $\mathrm{ZnO}$ & 0.0047 \\
8. & $\mathrm{SrO}$ & 0.0450 \\
9. & $\mathrm{Nb}_{2} \mathrm{O}_{5}$ & 0.0374 \\
10. & $\mathrm{MoO}_{3}$ & 0.2160 \\
11. & $\mathrm{Ag}_{2} \mathrm{O}$ & 0.0209 \\
12. & $\mathrm{CdO}_{1}$ & 0.0758 \\
13. & $\mathrm{Sb}_{2} \mathrm{O}_{5}$ & 0.0171 \\
14. & $\mathrm{HfO}_{2}$ & 0.0002 \\
15. & $\mathrm{Ta}_{2} \mathrm{O}_{5}$ & 0.0008 \\
16. & $\mathrm{PbO}$ & 0.0001 \\
\hline
\end{tabular}

Table 6: XRF Analysis of Rice Husk ash after heat treatment at $540^{\circ} \mathrm{C} / 60 \mathrm{~min} / 180^{\circ} \mathrm{C} / 180 \mathrm{~min}$

\begin{tabular}{lll}
\hline $\mathrm{S} / \mathrm{N}$ & $\mathrm{Component}$ & Mass $(\%)$ \\
\hline 1. & $\mathrm{SiO}_{2}$ & 79.3412 \\
2. & $\mathrm{P}_{2} \mathrm{O}_{5}$ & 0.4173 \\
3. & $\mathrm{~K}_{2} \mathrm{O}$ & 1.0159 \\
4. & $\mathrm{CaO}$ & 0.4058 \\
5. & $\mathrm{MnO}$ & 0.0809 \\
6. & $\mathrm{Fe}_{2} \mathrm{O}_{3}$ & 0.1962 \\
7. & $\mathrm{CuO}$ & 0.0008 \\
8. & $\mathrm{SrO}$ & 0.0350 \\
9. & $\mathrm{Nb}_{2} \mathrm{O}_{5}$ & 0.0382 \\
10. & $\mathrm{MoO}_{3}$ & 0.1700 \\
11. & $\mathrm{Ag}_{2} \mathrm{O}$ & 0.0196 \\
12. & $\mathrm{CdO}$ & 0.1098 \\
\hline
\end{tabular}

It was however observed that the total percentage of oxides determined by the XRF analysis was less than $100 \%$ implying that the machine could not detect further oxides. From literature, XRF study is known not to detect low atomic elements especially those elements lighter than sodium $(\mathrm{Na})$ due to the limitation of the instrument and its low X-ray yield for the light elements [19-20]. It was also observed that the percentage silica increased with further ashing as depicted in Table 6, but with a lower impurity level which was also observed in the XRD analysis.
3.3 XRD Analysis of the Rice Husk/Ash Used in these Study The XRD spectrum of rice husk (Figure 2 and 3) showed a broad peak at the $2 \Theta$ value of $22^{\circ}$, a characteristics of silica in amorphous form which is almost absent in Figure 4. After ashing and heat treatment, the RHA samples were black with some gray particles, implying encapsulated carbon residues. Sharp XRD peaks of the rice husk at $2 \Theta$ values of $26.6^{\circ}$ (Figures 2-4) indicates silica in the crystalline form. These reflection will give a corresponding d-value of 2.85 when used in Bragg's equation suggesting cristobalite form of reflections. These XRD peaks, therefore suggest that the rice husk used in these study has mixed phases of both forms of silica. 


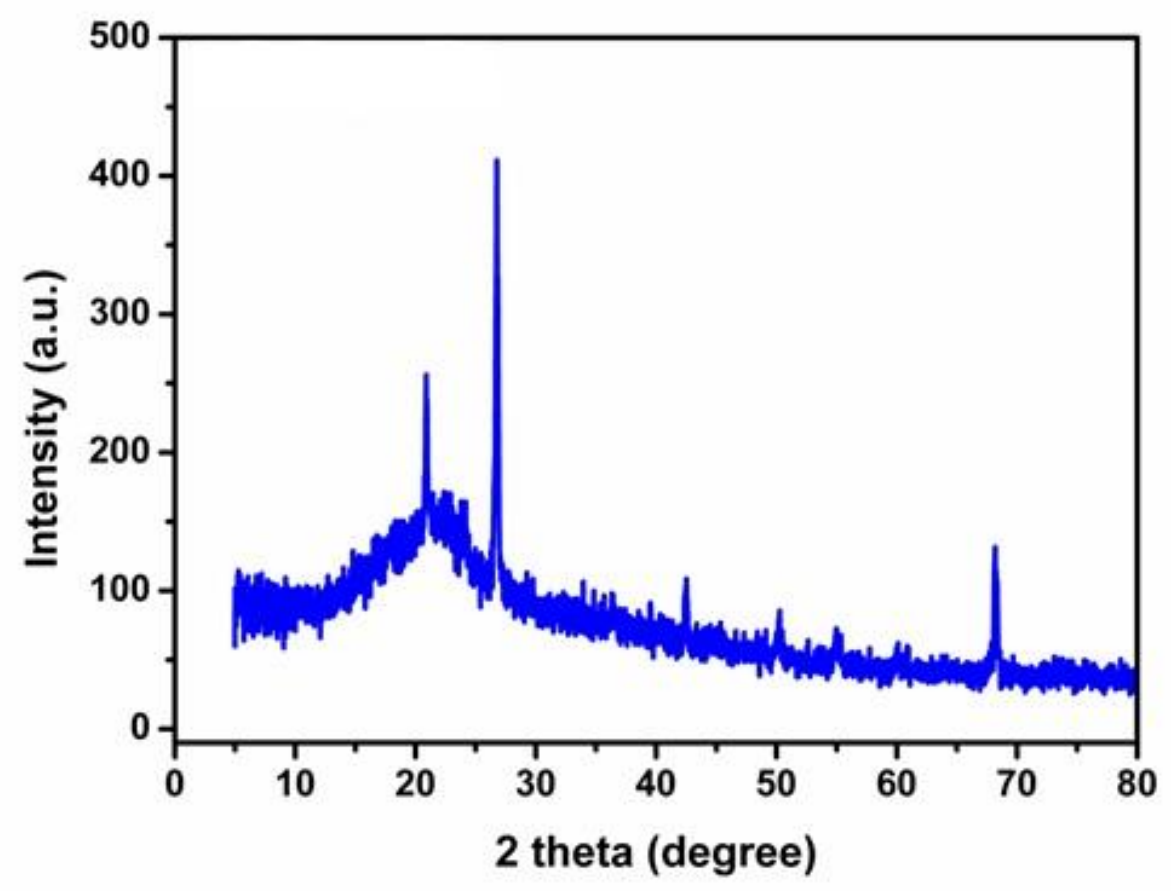

Figure 2: XRD analysis of rice husk used

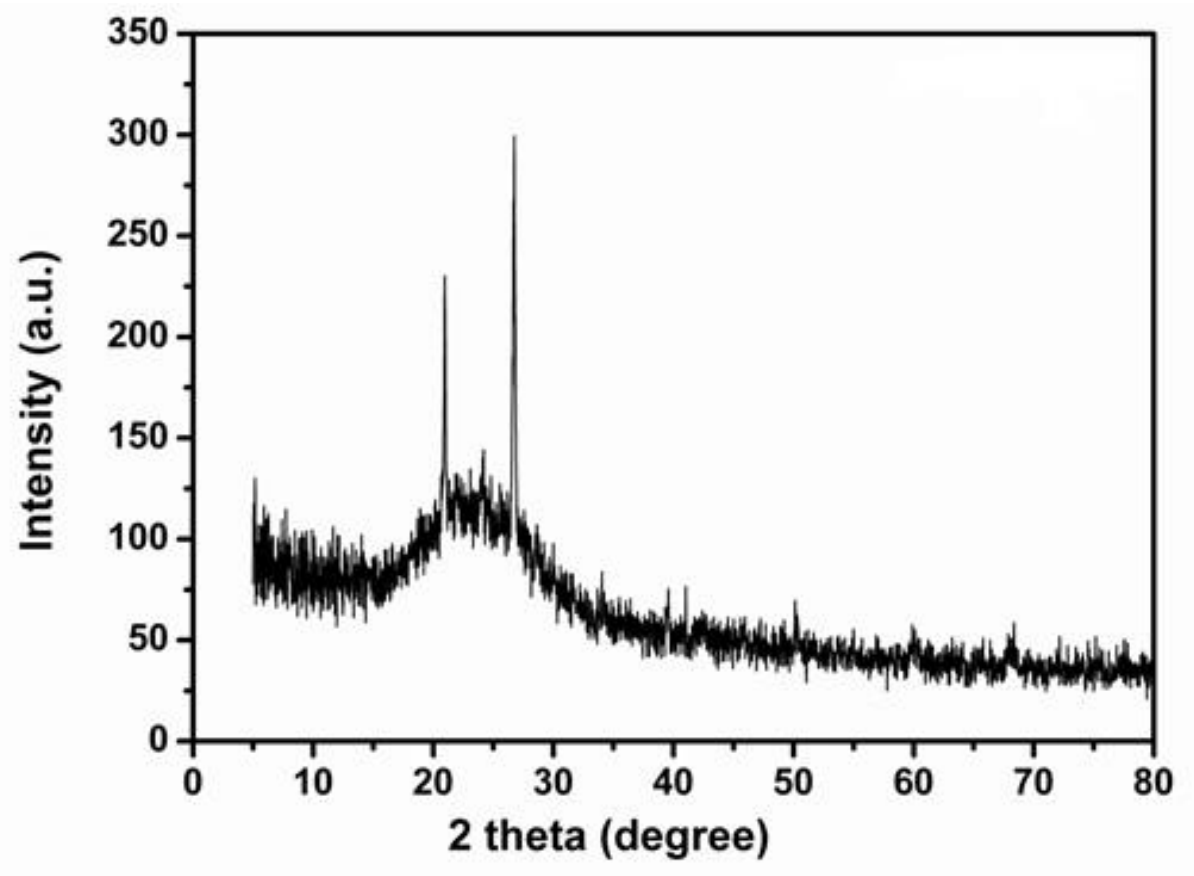

Figure 3: XRD analysis of rice husk ash produced 


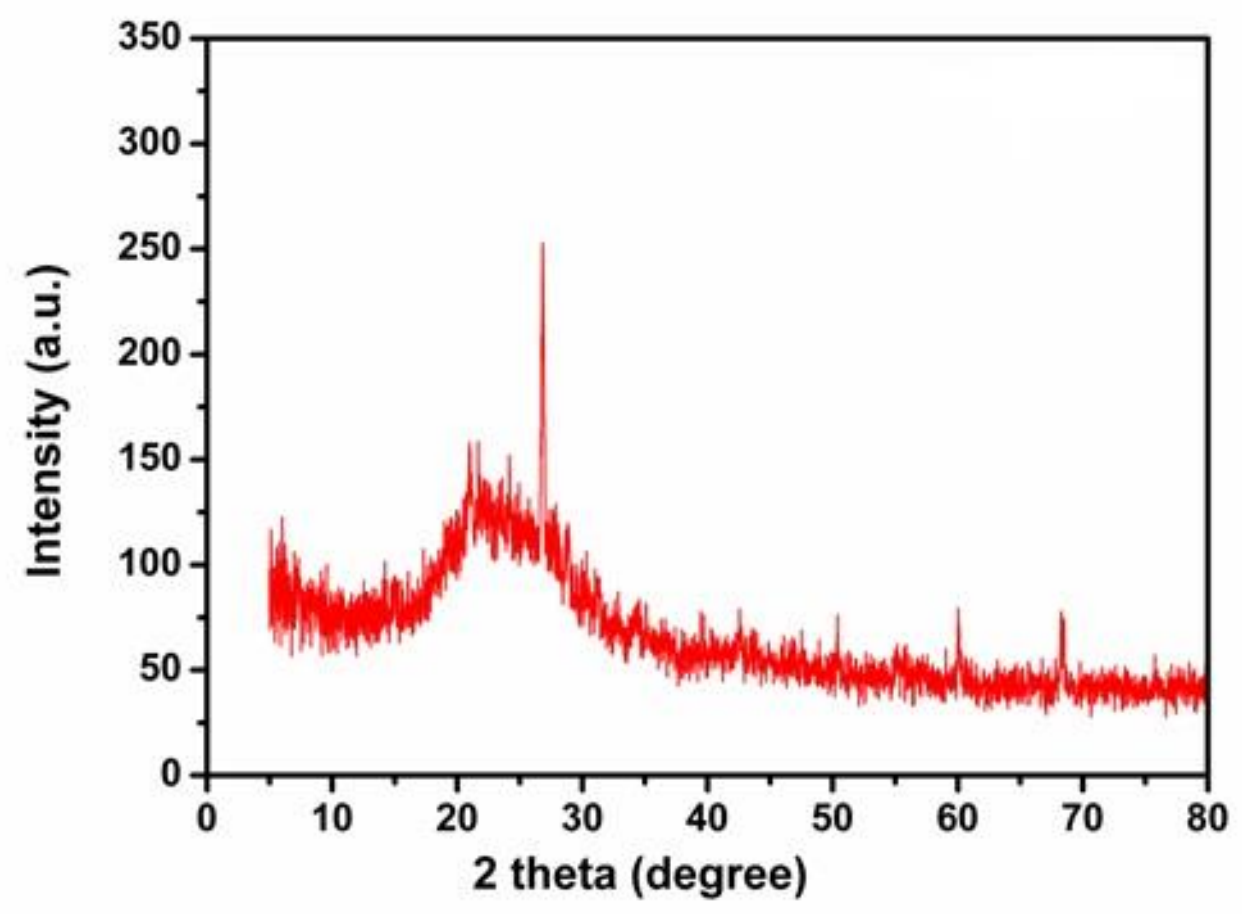

Figure 4: XRD analysis of rice husk ash after usage in heat treatment

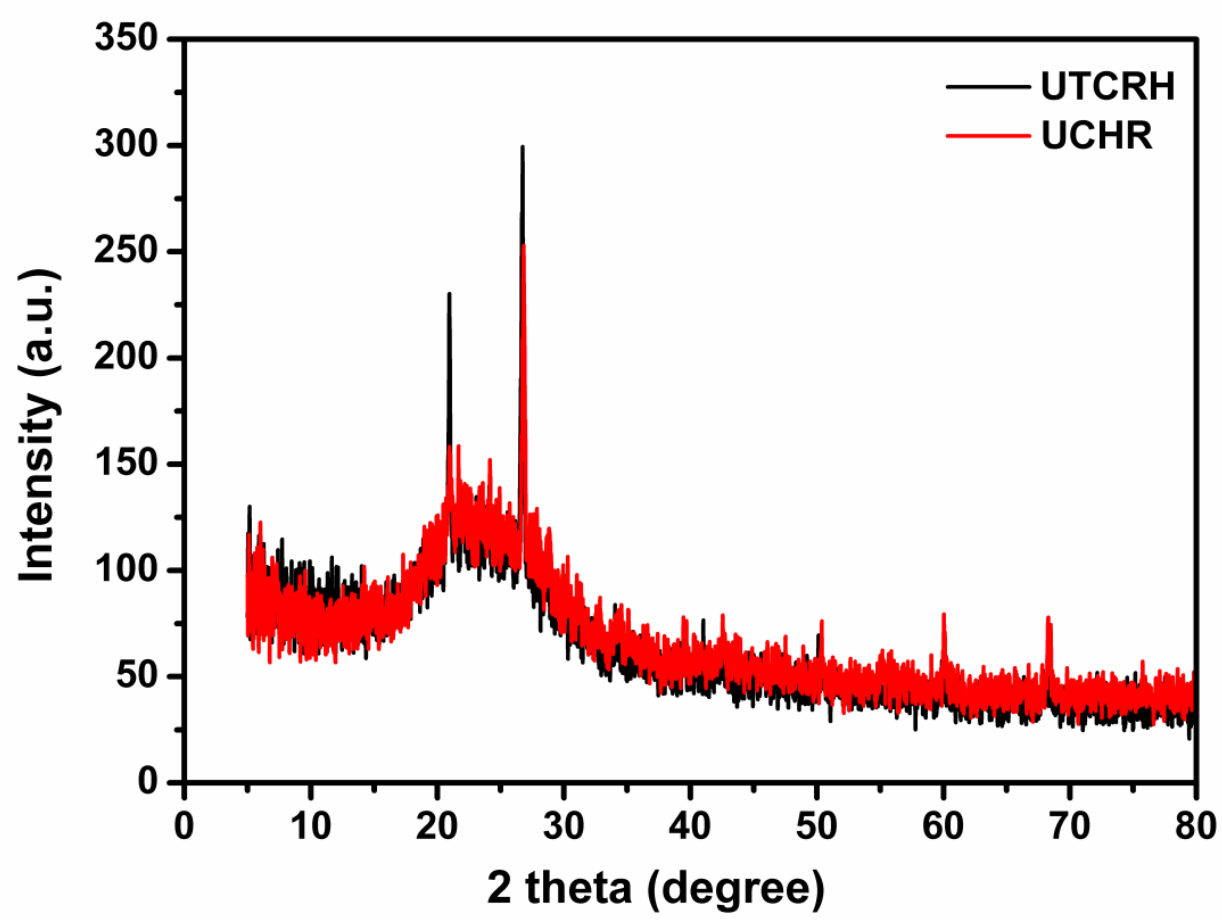

Figure 5: Combined XRD analysis of untreated (UTCRH) and treated (UCHR) ricehusk ash

In accordance with literature however, at higher temperatures, the silica in RHA would consist of crystobalite and some tridymite phases because of melting of the surfaces of the ash silica particles and particles bonding together. In these work however, all the condition of the rice husk indicated peaks at $26.6^{\circ}$ which was very predominant.
3.4 Wear Rate and Taguchi Analysis

The control factors were selected as Solution Heat Treatment temperature (SHT tempt), Solution Heat Treatment time (SHT time), ageing temperature and ageing time. The levels of each factor used is as reported in Table 2 and positioned in an L9 Taguchi design. The effect of the control factors on wear rate of the studied A356 aluminium alloy in the absence and presence of carbonized rice husk 
was studied. Each run was repeated at least three times and the average wear rate value was recorded with $\mathrm{S} / \mathrm{N}$ ratio. The $\mathrm{S} / \mathrm{N}$ ratio was calculated using the condition been smaller is the better.
3.4.1 Wear Rate of the Alloy after Conditioning the Heat Treatment

The average mean wear rate values measured is presented in Table 7, while Table 8 shows the $\mathrm{S} / \mathrm{N}$ response values. The results indicated that solution heat treatment time has the largest effect on the wear rate of the A356 aluminium alloy studied, followed by ageing temperature and ageing time. In this case, solution heat treatment temperature has the smallest effect on wear rate.

Table 7: Taguchi L9 orthogonal array, experimentally measured values of mean wear rate and their S/N ratio for conditioned A356 aluminium alloy

\begin{tabular}{|c|c|c|c|c|c|c|}
\hline \multirow[b]{2}{*}{ Run } & \multicolumn{3}{|c|}{ Control factor levels } & & \multicolumn{2}{|c|}{ Mean wear rate value } \\
\hline & $\mathrm{A}$ & $\mathrm{B}$ & $\mathrm{C}$ & $\mathrm{D}$ & Value $(\mathrm{mm} 3 / \mathrm{n} / \mathrm{m})$ & $\mathrm{S} / \mathrm{N}$ ratio $(\mathrm{dB})$ \\
\hline 1. & 500 & 30 & 160 & 60 & 0.5567 & 5.08758 \\
\hline 2. & 500 & 60 & 180 & 120 & 0.5515 & 5.16909 \\
\hline 3. & 500 & 90 & 200 & 180 & 0.5310 & 5.49811 \\
\hline 4. & 540 & 30 & 180 & 180 & 0.5208 & 5.66658 \\
\hline 5. & 540 & 60 & 200 & 60 & 0.5900 & 4.58296 \\
\hline 6. & 540 & 90 & 160 & 120 & 0.5977 & 4.47033 \\
\hline 7. & 580 & 30 & 200 & 120 & 0.5384 & 5.37790 \\
\hline 8. & 580 & 60 & 160 & 180 & 0.5770 & 4.77648 \\
\hline 9. & 580 & 90 & 180 & 60 & 0.5636 & 4.98058 \\
\hline
\end{tabular}

Table 8: $\mathrm{S} / \mathrm{N}$ ratio response $(\mathrm{dB})$ for wear rate in PCRH

\begin{tabular}{lcccc}
\hline Level & SHT temp $\left({ }^{\circ} \mathrm{C}\right)$ & SHT time $($ mins $)$ & AGEING temp $\left({ }^{\circ} \mathrm{C}\right)$ & AGEING time $(\mathrm{mins})$ \\
\hline 1. & 5.252 & 5.377 & 4.778 & 4.884 \\
2. & 4.907 & 4.843 & 5.272 & 5.006 \\
3. & 5.045 & 4.983 & 5.153 & 5.314 \\
Main effect & 0.345 & 0.535 & 0.494 & 0.430 \\
\hline
\end{tabular}

The results were then analyzed to find a combination of factors that will provide the maximum wear rate. Figures $6 \mathrm{a}$ and $6 \mathrm{~b}$ show the effect of control factors on the wear rate. It can be seen that the influence of SHT time and Ageing time is significant while SHT temperature and Ageing temperature are less significant. A fact which can also be concluded from the main effect values presented in Table 8 .

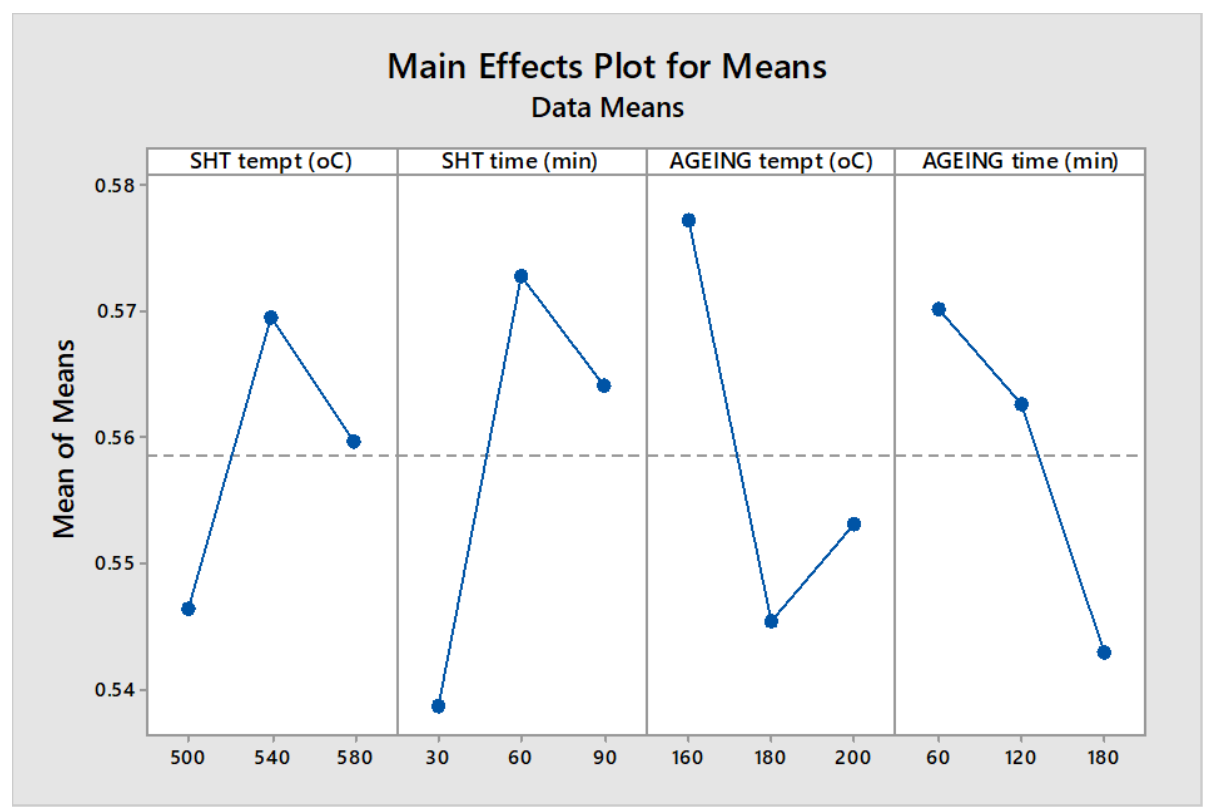

Figure 6a: Effect of process parameters on mean response characteristics of A356 aluminium alloy 


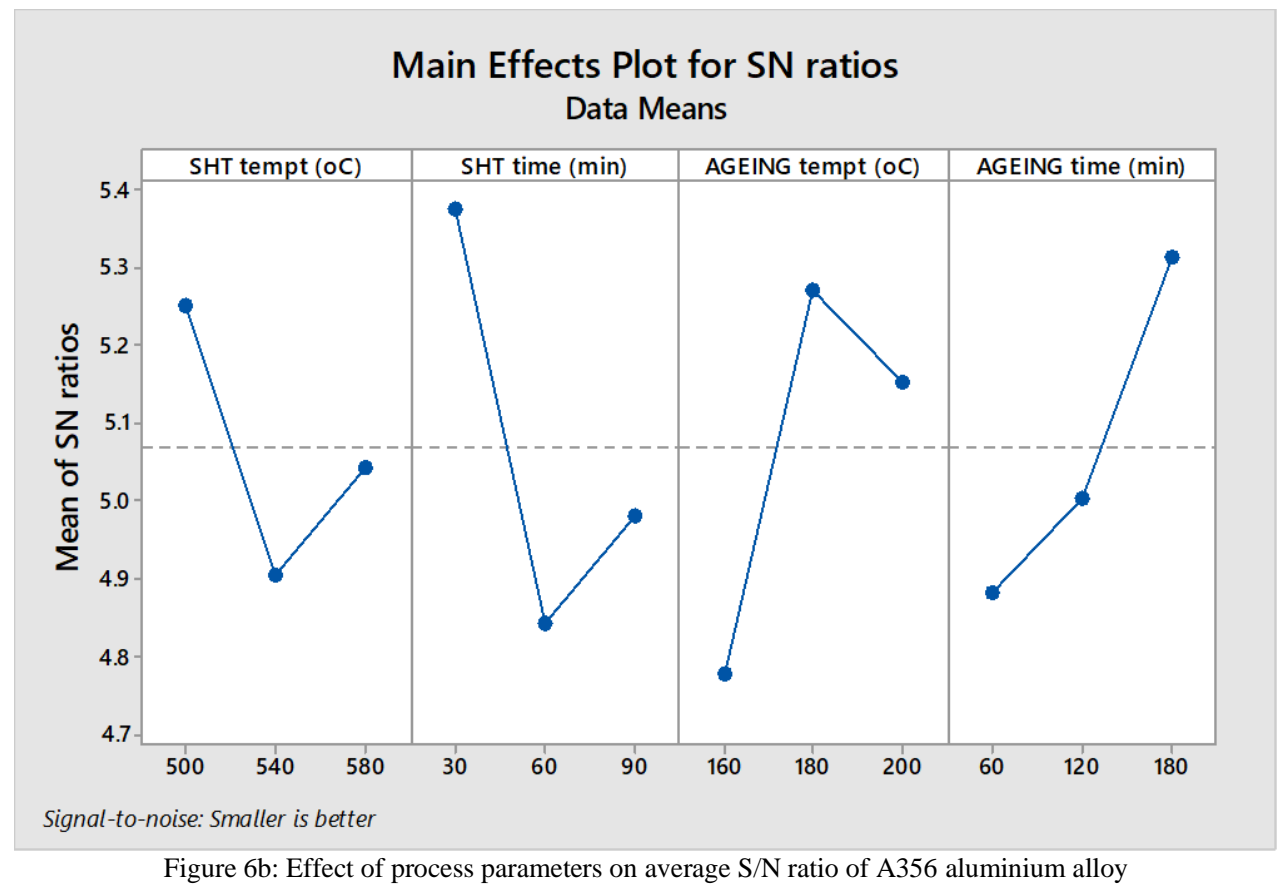

\subsubsection{Prediction for Optimized Wear Rate Value of A356 Aluminium Alloy}

The heat treated alloy in the presence of carbonized rice husk has been shown to have a better wear rate as compared with the as cast and conventionally treated A356 aluminium alloy. In predicting the appropriate heat treatment conditions based on the mean of mean values of wear rate shown in Figures $6 a$ and $b$ now becomes possible. Equally, analyzing the result have shown that a better wear rate can be obtained at levels $\mathrm{A}_{1}$ (SHT temperature of $500^{\circ} \mathrm{C}$ ), $\mathrm{B}_{1}$ (SHT time of 30 minutes), $\mathrm{C}_{2}$ (Ageing temperature of $180^{\circ} \mathrm{C}$ ) and $\mathrm{D}_{3}$ (Ageing time of 180 minutes).

\subsubsection{Developing Model for Predicting the Optimal Wear Rate of conditioned A356 Aluminium Alloy}

Let

$H_{m w p c}=$ Predicted mean wear rate of conditioned samples

$H_{S / N w p c}=$ Predicted $\mathrm{S} / \mathrm{N}$ ratios for wear rate of conditioned samples

$h_{m w p c}=$ Total average of wear rate performance characteristics [i.e. corresponding to all the $36(9 \times 4)$ readings in Table 7]

$h_{S / N w p c}=$ Total average of S/N ratio performance characteristics [i.e. corresponding to all the 36 (9x4) readings in Table 7]

$\bar{A}_{1}, \bar{B}_{1}, \bar{C}_{2}$ and $\bar{D}_{3}=$ The average values of the wear rate of conditioned samples with process parameters at their respective optimal levels.

Therefore,

$$
\begin{aligned}
& H_{m w p c}=\bar{h}_{m w p c}+\left(\bar{A}_{1}-\bar{h}_{m w p c}\right)+\left(\bar{B}_{1}-\bar{h}_{m w p c}\right)+\left(\bar{C}_{2}-\bar{h}_{m w p c}\right)+\left(\bar{D}_{3}-\bar{h}_{m w p c}\right) \\
& H_{S / N w p c}=\bar{h}_{S / N w p c}+\left(\bar{A}_{1}-\bar{h}_{S / N w p c}\right)+\left(\bar{B}_{1}-\bar{h}_{S / N w p c}\right)+\left(\bar{C}_{2}-\bar{h}_{S / N w p c}\right)+\left(\bar{D}_{3}-\bar{h}_{S / N w p c}\right)
\end{aligned}
$$

Equations (i) and (ii) can be used to predict the optimal mean and $\mathrm{S} / \mathrm{N}$ values for wear rate of the conditioned alloy. It should however be noted in this study that assumptions are made on the bases that no interaction between any of the factors $\mathrm{A}, \mathrm{B}, \mathrm{C}$ and $\mathrm{D}$ exist.

\subsubsection{Confirmation of the Predicted Wear Rate Value of A356 Aluminium Alloy}

To evaluate the validity of the analysis, a statistical analysis based on the predicted $\mathrm{S} / \mathrm{N}$ ratio and a set of experiments were conducted. Table 9 shows the comparisms between the predicted wear rate values and experimental results obtained.

\begin{tabular}{|c|c|c|c|c|c|c|c|c|c|}
\hline \multirow{2}{*}{$\begin{array}{l}\text { Response } \\
(\mathrm{mm} 3 / \mathrm{n} / \mathrm{m})\end{array}$} & \multirow[t]{2}{*}{ Level } & \multicolumn{2}{|c|}{ Predictive values } & \multicolumn{2}{|c|}{ Experimental values } & \multicolumn{2}{|c|}{ Percentage error } & \multicolumn{2}{|c|}{ Improvement } \\
\hline & & $\begin{array}{c}\text { Mean } \\
(\mathrm{mm} 3 / \mathrm{n} / \mathrm{m})\end{array}$ & $\mathrm{S} / \mathrm{N}(\mathrm{dB})$ & $\begin{array}{l}\text { Mean } \\
(\mathrm{mm} 3 / \mathrm{n}\end{array}$ & & Mean & & Value & \\
\hline $\mathrm{W}_{\text {PCRH }}$ & $\mathrm{A}_{1} \mathrm{~B}_{1} \mathrm{C}_{2} \mathrm{D}_{3}$ & 0.4977 & 6.01155 & 0.4921 & 6.15893 & 1.14 & 2.39 & 0.0287 & 5.139 \\
\hline
\end{tabular}

Table 9: Comparisms between the predicted wear rate values and experimental results of conditioned heat treated samples 
The percentage error in mean wear rate of conditioned sample is 1.14. Which however is less than the maximum recommended $10 \%$ error reported in literature [19-22]. The percentage improvement in wear rate of 5.139 in the conditioned samples showed that the wear rate of the A356 aluminium alloy can be further increased by the use of Taguchi design of experiment. Also, the improvement in the presence of carbonize rice husk showed that the carbonized rice husk can be used to further enhance the wear rate properties of the alloy under investigation.

\section{The following conclusions can be drawn from the present study}

1. The textural analysis conducted on the rice husk ash showed that there is an enhanced rice husk condition, since rice husk of higher diameter have a higher diffusion rate. The surface area data using various method range from $1.344 \times 104 \mathrm{~m} 2 / \mathrm{g}$ (Lagmore surface data) to $8.714 \times 10 \mathrm{~m} 2 / \mathrm{g}$ (DFT cumulative surface area), pore volume from $9.279 \times 10-3 \mathrm{cc} / \mathrm{g}$ (SF method) to $5.757 \times 10-2 \mathrm{cc} / \mathrm{g}$ (HK method) and pore size from $1.847 \mathrm{~nm}$ (HK method) to $6.538 \mathrm{~nm}$ (DR method).

2. The XRF conducted on rice husk/ash showed that as temperature/time of ashing is increased, the silica content in the rice husk also increased i.e. $27.3418 \%$ in the as received condition (rice husk), $63.1660 \%$ of $\mathrm{SiO} 2$ as rice husk ash and $79.3412 \%$ of $\mathrm{SiO} 2$ after using the ash in the heat treatment process. The percentage of other impurities decreased as temperature was increased. The XRD peaks suggested that rice husk used in this study has mixed phases of both forms of silica as shown in the peaks at $2 \Theta\left(22^{\circ}\right)$ and $2 \Theta\left(26.6^{\circ}\right)$.

3. Heat treating the aluminium alloy in the presence of silica will lead to the formation of silicon metal which dissolves in the alloy leading to further improvement in properties. This was further seen in the conditioned alloy having a lower wear rate in almost all the heat treatment conditions as compared with the as cast and conventionally treated samples.

4. The L9 Taguchi analysis conducted showed that the lowest wear rate is achieved at A1B1C2D3. The predicted value of mean wear rate at this condition was $0.4977 \mathrm{~mm}^{3} / \mathrm{n} / \mathrm{m}$ which decreased to 0.4921 $\mathrm{mm}^{3} / \mathrm{n} / \mathrm{m}$ after validation, indicating a percentage improvement of $5.139 \%$.

\section{REFERENCES}

[1] Abhang, S. R and Bhaskar, D. P. Design and Analysis of disc brake. International journal of Engineering trends and technology (IJETT) (2014) 8 (4) 165-167. ISSN: 2231-5381

[2] Gwozdz, M and Kwapisz K. Influence of ageing process on the microstructure and mechanical properties of aluminium-silicon cast alloys - Al-9\%Si-3\% Cu and Al-9\%Si-0.4\%Mg, Bachelors thesis, (2008) Castings Jönköping University, Sweden

[3] Alnaqi, A, A. Characterisation of coated light weight brake rotors. $\mathrm{PhD}$ dissertation, School of Mechanical Engineering, (2014) University of Leeds.
[4] Agbeleye, A. A., Esezobor, D. E., Balogun, S. A., Agunsoye, J. O., Solis, J., Neville, A. Tribological properties of aluminium-clay composites for brake disc rotor applications. Journal of King Saud University-Science. http://dx.doi.org/10.1016/j.jksus.2017.09.002

(2017)

[5] Burkinshaw, M., Neville, A., Morina, A., Sutton, M. Calcium sulphonate and its interactions with ZDDP on both aluminiumsilicon and model silicon surfaces. Tribology International. (2012) $46,41-51$.

[6] Abdulwahab, M., Umaru, O.B., Bawa, M.A., Sani, L.M., Raymond, N. Investigation of the wear characteristics of Al-Si-Mg alloy under conditioned thermal treatment.Nigerian Research Journal of Engineering and Environmental Sciences (2017) 2(1) pp. 59-64.

[7] Abdulwahab, M., Madugu, I. A., Yaro, S. A., Hassan, S. B., Popoola, A. P. I. Effect of multiple-step thermal ageing treatment on the hardness characteristics of A356.0-type Al-Si-Mg alloy. Materials and design (2011) 32(3) 1159-1166.

[8] Alsaif, M. A., Dahm, K. L., Shrestha, S., Dearnley, P. A., and Barton, D. C. Plasma Electrolytic Oxidation (PEO) treated aluminium metal matrix composite rotors for lightweight automotive brakes, (2010) France.

[9] Umaru, O. B. Influence of pre-ageing thermal condition on the hardness and corrosion characteristics of A356.0 type Al-Si-Mg alloy. (2013) (Unpublished Masters of Science thesis).Department of Metallurgical and Materials Engineering, Ahmadu Bello University, Zaria, Nigeria.

[10] Milala, M.A., Shugaba, A., Gidado, A., Ene, A.C and Wafar, J.A. Studies on the use of Agricultural wastes for cellulose enzyme production by Aspegillusniger. Research journal of Agriculture and Biological Sciences. (2005) 1(4), 325-328

[11] Narayanasamy, P., Selvakumar, N. Tensile, compressive and wear behavior of self-lubricating sintered magnesium based composites. Transaction of Nonferrous Metallurgical Society of China (2016) 27, 312-323.

[12] Sahu, S. V., Satapathy, A., Patnaik, A., Sreeku,mar, K. P., Ananthapadmanabhan, P. V. Development, Characterization and erosion wear response of plasma sprayed fly ash-aluminium coatings. Matrials and Design, (2010) 31 pp. 1165-1173.

[13] Ezzedin., M. A. Feasibility and optimization of dissimilar laser welding components, PhD thesis, School of Mechanical and Manufacturing Engineerig, (2008) Dubin city University, Ireland.

[14] Kumar, A., Motwani, Y., Otero, L. An application of Taguchi's robustexperimental design technique to improve service performance, International Journalof Quality \& Reliability Management, (1996)Vol. 13 No. 4, pp. 85-98.

[15] Anawa, E. M., Olabi, A. G., Hashmi, M. S. J. Application of Taguchi Method to Optimize Dissimilar Laser Welded Components, presented at 23rd International Manufacturing Conference, (2006) Belfast, UK, . 241-248.

[16] Hutchings I M. Tribology. Friction and Wear of Engineering Materials. Ed. EdwardArnold. (1992) ISBN: 0-340-56184-X.

[17] Mahapatra, S. S and Patnaik, A. Study on mechanical and erosion wear behavior of hybrid composites using Taguchi experimental design, Materials and design, (2009) 30, pp. 2791-2801.

[18] Mandal, N; Doloi, B; Mondal, B; Das, R. Optimization of flank wear using zirconia toughened alumina (ZTA) cutting tool: Taguchi method and regression analysis, Measurement, (2011) 44 pp2140-2155.

[19] Omatola, K. M and Onoja, A. D. Elemental analysis of ricehusk ash X-ray Fluorescence technique, International journal of physical sciences, (2009) vol. 4 (4) pp. 189-193. ISSN 1992-1950.

[20] Jenkins R. X - Ray Fluorescence Spectrometry. Wiley Inter science, (1999) New York. pp. 5-7.

[21] Sethi V. Effect of aging on abrasive wear resistance of silicon carbide particle reinforced aluminium matrix composite, Masters of Science thesis submitted to the division of graduate studies and research of the University of Cincinnati (2007).

[22] Sug Won Kim, Ui Jong Lee, Sang won Han, Dong keunkim and Ogi K. Heat treatment and wear characteristics of $\mathrm{Al} / \mathrm{SiCp}$ composites fabricated by duplex process", Composites: (2003) Part B, Vol. 34, pp. 737:745, 